\title{
Preoperative Anaemia and Associated Postoperative Outcomes in Noncardiac Surgery Patients in Central Region of Ghana
}

\author{
Gladys Amponsah ${ }^{1}$ and Alice Charwudzi ${ }^{2}$ \\ ${ }^{1}$ Department of Anaesthesia and Pain Management, School of Medical Sciences, University of Cape Coast, Cape Coast, Ghana \\ ${ }^{2}$ Department of Chemical Pathology, School of Medical Sciences, University of Cape Coast, Cape Coast, Ghana \\ Correspondence should be addressed to Gladys Amponsah; gamponsah2006@yahoo.com
}

Received 21 August 2017; Revised 30 October 2017; Accepted 14 November 2017; Published 11 December 2017

Academic Editor: Ronald G. Pearl

Copyright ( 2017 Gladys Amponsah and Alice Charwudzi. This is an open access article distributed under the Creative Commons Attribution License, which permits unrestricted use, distribution, and reproduction in any medium, provided the original work is properly cited.

\begin{abstract}
Introduction. Several studies suggest that preoperative anaemia (PA) is associated with adverse postoperative outcomes, but little is known about these outcomes in the Central Region of Ghana. This study aims to determine the prevalence of PA among noncardiac surgical patients and its implications for their postoperative outcomes. Methods. This study was designed as an observational study; data including demographics and clinical and laboratory results were collected from the patients' records and through interviews. Results. A total of 893 inpatient surgical cases undergoing elective and emergency operations, aged 15 years and above with mean age of $44.2 \pm 17.0 \mathrm{yrs}$, were enrolled. The prevalence of PA was $54.3 \%$, mostly microcytic with or without hypochromia $(57.2 \%)$. The prevalence was higher in females than males $(p \leq 0.001)$. Preoperative anaemia was significantly associated with prolonged length of hospital stay (OR: 2.12 (95\% CI: 1.49-3.10)). Allogeneic blood transfusion significantly prolonged the length of hospital stay (OR 4.48 (95\% CI: $2.67-7.51)$ ). $15.5 \%$ of the anaemic patients received oral iron supplements compared to $2.2 \%$ of nonanaemic patients $(p \leq 0.001)$. Conclusion. Preoperative anaemia is common among noncardiac surgical patients. It is independently and significantly associated with prolonged hospital stay leading to the use of increased healthcare resources. It is also the main predictor for perioperative allogeneic blood transfusions and the use of haematinics.
\end{abstract}

\section{Introduction}

Anaemia is an important public health concern that has negative impact on an individual's health as well as the economic potential of the population [1]. The prevalence of anaemia depends on age, sex, and associated comorbidities such as diabetes, hypertension, and inflammatory conditions [2].

Preoperative anaemia is not an uncommon finding, and depending on the cohort being investigated, the prevalence can be as high as 75\% [3]. Preoperative anaemia increases the risk of oxygen depletion, thereby increasing the risk of unfavourable postoperative outcomes [3]. These patients are either given large amounts of red blood cell transfusions depending on the severity of the anaemia [4] or in nonurgent cases necessitating the postponement of surgery [5] till the haemoglobin concentration stabilises or normalises.
Allogeneic blood transfusion is independently associated with increased risk of infection and other adverse postoperative outcomes, especially in countries with low or medium human development index $[6,7]$. Furthermore, the treatment of preoperative anaemia with RBC transfusions is more costly as compared to correcting anaemia with haematinics like iron, vitamin $B_{12}$, folate, or erythropoietin substitutes preoperatively [8]. Blood transfusion therapy may also increase the risk of transfusion transmissible infections (TTIs) and alloimmunization in a low-to-middle income country such as Ghana. The estimated TTI risk for HIV, HBV, and HCV from a unit of transfused blood in sub-Saharan Africa is 1, 4.3, and 2.5 infections per 1000 units, respectively, based on a mathematical projection [9]. These three microbiological agents and syphilis are the ones routinely screened in Ghana.

Malaria, a multiorgan systemic disease, can cause and aggravate anaemia, constituting an additional risk in surgical procedures. Studies have demonstrated high rates of morbidity 
and mortality after surgery in anaemic patients with Plasmodium falciparum associated malarial disease [10]. In addition to anaemia, other confounding factors such as the comorbid conditions can also impede the postoperative progress of the patient [8].

Preoperative haemoglobin levels are checked before surgery in most patients in Ghana. As far as we are aware, no studies have explored the implications of preoperative anaemia on postoperative outcomes in Ghana. This study was therefore carried out to determine the prevalence of preoperative anaemia in unselected noncardiac surgery patients and their outcomes following surgery in the Central Region of Ghana.

\section{Materials and Methods}

This study was designed as an observational study and was carried out from June 2015 to July 2016 in two selected hospitals in the Central Region of Ghana. Ethical approval for the study was obtained from the Institutional Review Board of the University of Cape Coast (approval reference: UCC/IRB/3/1). Written permission was also sought from the Management of the Cape Coast Teaching Hospital, Cape Coast, and Saint Luke's Catholic Hospital, Apam. Written informed consent was obtained from individual patients or their guardians. Eligible patients aged 15 and above had a preoperative assessment within 40 days prior to surgery with at least one preoperative haemoglobin $(\mathrm{Hb})$ level to undergo elective or emergency surgery were recruited. Exclusion criteria included planned day-case surgery and obstetric procedures $[3,7,8]$. Data were collected using the patient's medical record, operation logbooks, anaesthetic records, nurses review notes, and interviews/interaction with surgeons on admission and discharge of the patient. Data were entered into an Excel 2010 sheet anonymously. Patients who were on admission for more than 15 days before surgery, patients who were on admission for more than 30 days after surgery and those with incomplete data such as missingdate of discharge were excluded from the data analysed. Participation did not require any additional visits or assessments. When data collection was not completed before discharge, the participant's medical record was retrieved from the medical records unit. The administration of RBC and haematinics followed the selected hospitals' protocols. A review of the autologous donation records and interview with the blood bank organiser were used to obtain data on autologous donation and the cost of processing a unit of whole blood. Relatives of patients who brought in replacement donors were also interviewed on the cost of presenting a single possible donor.

2.1. Data Collection. Data were collected on patients' characteristics (sex and age), date of admission, date of surgery, date of discharge, preoperative full blood count result, type of anaesthesia (general or regional), type of surgery done, duration of surgery, comorbidity, sickling status, presence of malaria parasites, date of inhospital mortality, complications before discharge, and date of RBC transfusion. The primary outcome measured was preoperative anaemia. Secondary outcomes were postoperative adverse events resulting in complications before discharge, prolongation of hospitalization, the prevalence of perioperative allogeneic blood transfused, and inhospital mortality. Patients were followed up until they were discharged from the hospital. Complete patient confidentiality was maintained.

2.2. Definitions. Preoperative haemoglobin $(\mathrm{Hb})$ levels were the last $\mathrm{Hb}$ estimated within 40 days prior to the index operation; majority of the participants 773 (86.6\%) had their last $\mathrm{Hb}$ estimated within two weeks prior to the index surgery. The World Health Organization (WHO) criteria for anaemia (women $12.0 \mathrm{~g} / \mathrm{dl}$ and men $13.0 \mathrm{~g} / \mathrm{dl}$ ) and its subclassifications (nonpregnant women 15 years of age and above: mild: $11.0-11.9 \mathrm{~g} / \mathrm{dl}$, moderate: $8.0-10.9 \mathrm{~g} / \mathrm{dl}$, severe: lower than $8.0 \mathrm{~g} / \mathrm{dl}$; men 15 years of age and above: mild: $11.0-12.9 \mathrm{~g} / \mathrm{dl}$, moderate: $8.0-10.9 \mathrm{~g} / \mathrm{dl}$, severe: lower than $8.0 \mathrm{~g} / \mathrm{dl})$ were used [11]. Morphological examination of peripheral blood film for anaemia classification was not routinely performed at the selected centres. Hence, anaemia was classified based on mean corpuscular volume (MCV) and/or mean corpuscular haemoglobin $(\mathrm{MCH})$ into (i) normocytic normochromic types $(\mathrm{MCV} \geq 80$ but $<100 \mathrm{fl}$; $\mathrm{MCH} \geq 27 \mathrm{pg}$ ): primary aetiology likely to be anaemia of chronic disease, (ii) microcytic $(\mathrm{MCV}<80 \mathrm{fl})$ and/or hypochromic types $(\mathrm{MCH}<27 \mathrm{pg})$ : possible iron deficiency, and (iii) macrocytic types $(\mathrm{MCV} \geq 100 \mathrm{fl})$ : possible folate or $\mathrm{B}_{12}$ deficiency. The surgical procedures (grade of surgery) were classified using the BUPA Schedule of Procedures [12].

Postoperative outcomes included inhospital mortality, prolonged length of hospital stay (LOS) after surgery, and the development of postoperative infection or other complications such as cardiogenic shock before discharge and perioperative blood transfusion. Prolonged LOS was categorized as the proportion of patients with hospital stay greater than the 75 th percentile ( 8.0 days), as used by other studies $[13,14]$.

2.3. Statistical Analysis. Descriptive statistical analysis: continuous data were presented as mean, standard deviation (SD), or minimum and maximum values; categorical data were presented as the number and percentage of individuals in each category; and Pearson's chi-square test was used to compare the proportions between two groups.

Binary logistic regression models were performed using adjusted odds ratios (ORadj) to assess the independent effects of preoperative anaemia on length of hospital stay, postoperative complications, inhospital mortality, and perioperative RBC transfusion. Only factors remaining statistically significant $(p<0.05)$ from the univariate analysis (sex, surgical specialty, and comorbid conditions) and factors that had been theoretically proven to have effects (i.e., age, grade of surgery, and cancer) were used in the final model as covariates. Patients with severe and moderate anaemia were analysed together due to small numbers for the severely anaemic.

Analysis was performed with IBM SPSS statistical package version 21.0, USA. 
TABLE 1: Patient baseline characteristics.

\begin{tabular}{|c|c|c|c|c|}
\hline Parameter & Total $(n=893)$ & Preoperative anaemia $(n=485)$ & No preoperative anaemia $(n=408)$ & $p$ value \\
\hline Age, mean (range) & $44.2(16-90)$ & $45.3(16-90)$ & $43.0(16-85)$ & 0.326 \\
\hline $15-49$ years & $565(63.3 \%)$ & $297(61.2 \%)$ & $268(65.7 \%)$ & 0.370 \\
\hline 50 years and above & $328(36.7 \%)$ & $188(38.8 \%)$ & $140(34.3 \%)$ & - \\
\hline Sex, $n(\%)$ & & & & $<0.001$ \\
\hline Females & $454(50.8 \%)$ & $293(60.4 \%)$ & $161(39.5 \%)$ & - \\
\hline Males & $439(49.2 \%)$ & $192(39.6 \%)$ & $247(60.5 \%)$ & - \\
\hline \multicolumn{5}{|l|}{ Preoperative $\mathrm{Hb}$ concentration } \\
\hline Mean $\mathrm{Hb} \pm \mathrm{SD}$ & $12.0+2.5 \mathrm{~g} / \mathrm{dl}$ & $10.3 \pm 1.8 \mathrm{~g} / \mathrm{dl}$ & $14.1 \pm 1.3 \mathrm{~g} / \mathrm{dl}$ & $<0.001$ \\
\hline Classification of anaemia* & $n=804$ & $n=428$ & $n=376$ & $<0.001$ \\
\hline Microcytic and/or hypochromatic & $396(49.3 \%)$ & $245(57.2 \%)$ & $151(40.2 \%)$ & - \\
\hline Normocytic normochromic & $400(49.7 \%)$ & $179(41.8 \%)$ & $221(58.8 \%)$ & - \\
\hline Macrocytic & $8(1.0 \%)$ & $4(0.9 \%)$ & $4(1.1 \%)$ & - \\
\hline Grade of surgery, $n(\%)^{* *}$ & & & & 0.360 \\
\hline Minor & $31(3.5 \%)$ & $17(3.5 \%)$ & $14(3.4 \%)$ & - \\
\hline Intermediate & $180(20.2 \%)$ & $103(21.2 \%)$ & $77(18.9 \%)$ & - \\
\hline Major & $672(75.3 \%)$ & $360(74.2 \%)$ & $312(76.5 \%)$ & - \\
\hline Complex major & $10(1.1 \%)$ & $5(1.0 \%)$ & $5(1.2 \%)$ & - \\
\hline Surgical specialty, $n$ (\%) & & & & $<0.001$ \\
\hline General surgery & $583(65.3 \%)$ & $290(59.8 \%)$ & $293(71.8 \%)$ & - \\
\hline Gynaecology & $147(16.5 \%)$ & $119(24.5 \%)$ & $28(6.9 \%)$ & - \\
\hline Orthopaedics & $49(5.5 \%)$ & $19(3.9 \%)$ & $30(7.4 \%)$ & - \\
\hline Urology & $51(5.7 \%)$ & $26(5.4 \%)$ & $25(6.1 \%)$ & - \\
\hline Plastics & $24(2.7 \%)$ & $12(2.5 \%)$ & $12(2.9 \%)$ & - \\
\hline Ear, nose, and throat (ENT) & $24(2.7 \%)$ & $13(2.7 \%)$ & $11(2.7 \%)$ & - \\
\hline Maxillofacial & $15(1.7 \%)$ & $6(1.2 \%)$ & $9(2.2 \%)$ & - \\
\hline
\end{tabular}

Results are shown as mean (range), mean $( \pm \mathrm{SD})$, and frequency (percentage); $\%=$ percentage of patients; $\mathrm{Hb}=$ haemoglobin; ${ }^{*}$ data on $\mathrm{MCV}$ and $\mathrm{MCH}$ were available on $804(90.0 \%)$ patients; ${ }^{* *}$ grade of surgery was classified using the BUPA Schedule of Procedures [12].

\section{Results}

3.1. Patient Characteristics. In all, 953 eligible patients were enrolled in the study. 60 (6.3\%) patients were excluded. The excluded patients included patients whose period of admission days was outside those used in the analysis (48), patients with incomplete data (6), and patients with miscellaneous reasons such as high $\mathrm{Hb}(6)$. Hence, after data cleaning, 781 (87.5\%) patients from a tertiary hospital and 112 (12.5\%) from a mission hospital were included in the analysis. The details of the patient's characteristics are shown in Tables 1 and 2.

$433(48.5 \%)$ patients had general anaesthesia (GA), 434 (48.6\%) had subarachnoid spinal block (SAB), 10 (1.1\%) had SAB and GA, and $16(1.8 \%)$ had other anaesthesias such as local infiltration. There were a total of 624 (69.9\%) elective cases out of which $342(54.8 \%)$ were anaemic, and 269 (30.1\%) emergency cases out of which 143 (53.2\%) were anaemic. The overall median operating time (interquartile) was 76.0 minutes $(50.0,111.0$ minutes $)$.

3.2. Prevalence of Preoperative Anaemia. Patients with preoperative anaemia accounted for $54.3 \%$ of the study population, out of which 209 (23.4\%) presented with mild anaemia, $226(25.3 \%)$ with moderate anaemia, and 50 (5.6\%) with severe anaemia. The sex distribution, the mean $\mathrm{Hb}$, the severity, and the classification of the anaemia as well as surgical specialty are shown in Table 1. Age did not differ among the groups $(p=0.326)$. The significant association of anaemia and comorbidity is shown in Table 2. Hypertension was the most common comorbidity associated with anaemic patients.

When excluded data were included in the analysis, prevalence of preoperative anaemia was 55.2\%; it did not skew the anaemia prevalence.

3.2.1. Age and Sex Stratification of Anaemic Patients. The anaemia was more predominant among the 15-49 years group than the $50-90$ years $(p=0.003)$. Using this stratification, comorbidity, severity, and classification of the anaemia are shown in Table 3.

Elderly patients (65 years and above) constituted 133 (14.9\%) of the study population. The elderly group recorded the highest prevalence of preoperative anaemia $82(61.7 \%)$ compared to those below 65 years $(53.0 \%)(p=0.065) .44$ of 82 (53.7\%) had mild anaemia with only $8(9.8 \%)$ presenting with severe anaemia. The anaemia type was mainly normocytic normochromic $(45 / 70 ; 64.3 \%)$ as compared to anaemic patients $(167 / 358 ; 46.6 \%)$ below 65 years $(p=0.021)$. Also, 36 
TABLE 2: Patient baseline characteristics.

\begin{tabular}{|c|c|c|c|c|}
\hline Parameters & Total $(N=893)$ & Preoperative anaemia $(n=485)$ & No preoperative anaemia $(n=408)$ & $p$ value \\
\hline Comorbidities & & & & 0.028 \\
\hline Hypertension & $68(7.6 \%)$ & $40(8.2 \%)$ & $28(6.8 \%)$ & - \\
\hline Diabetes mellitus & $28(3.1 \%)$ & $22(4.5 \%)$ & $6(1.5 \%)$ & - \\
\hline Diabetes mellitus + hypertension & $27(3.0 \%)$ & $22(4.5 \%)$ & $5(1.2 \%)$ & - \\
\hline HIV & $9(1.0 \%)$ & $5(1.0 \%)$ & $4(1.0 \%)$ & - \\
\hline Asthma & $6(0.7 \%)$ & $3(0.6 \%)$ & $3(0.7 \%)$ & - \\
\hline Hepatitis B & $5(0.6 \%)$ & $3(0.6 \%)$ & $2(0.5 \%)$ & - \\
\hline Diabetes mellitus + other conditions* & $4(0.4 \%)$ & $2(0.4 \%)$ & $2(0.5 \%)$ & - \\
\hline Others ${ }^{*}$ & $5(0.6 \%)$ & $3(0.6 \%)$ & $2(0.5 \%)$ & - \\
\hline Cancer & $50(5.6 \%)$ & $31(6.4 \%)$ & $19(4.7 \%)$ & 0.261 \\
\hline Sickling status $(N=497)^{* *}$ & & & & 0.101 \\
\hline Positive & $52(10.5 \%)$ & $33 / 262(12.6 \%)$ & $19 / 235(8.1 \%)$ & - \\
\hline Negative & $445(89.5 \%)$ & $229 / 262(87.4 \%)$ & $216 / 235(91.9 \%)$ & - \\
\hline Preoperative malaria parasites $(N=600)^{* *}$ & & & & 0.456 \\
\hline Positive & $16(2.7 \%)$ & $10 / 320(3.1 \%)$ & $6 / 280(2.1 \%)$ & - \\
\hline Negative & $584(97.3 \%)$ & $310 / 320(96.9 \%)$ & $274 / 280(97.9 \%)$ & - \\
\hline
\end{tabular}

Results are shown as frequency (percentage); * diabetes mellitus with or without hypertension + (peptic ulcer disease or asthma or pneumonia); ${ }^{*}$ alcoholic liver disease, chronic kidney disease, and chronic skin ulcer; ${ }^{* *}$ sickling and preoperative malaria results were available for 497 and 600 patients, respectively.

(43.9\%) of the anaemic elderly patients had comorbid conditions compared to $13(25.5 \%)$ for the nonanaemic patients $(p=0.027)$.

3.3. Postoperative Outcomes. Evaluation of postoperative outcomes included the length of hospital stay after surgery, postoperative complications before discharge, and inhospital mortality.

(a) Length of hospital stay: preoperative anaemia patients had a significantly higher mean length of hospital stay (6.5 days; range: $1-29$ days) than nonanaemic patients (4.8 days; range: $1-27$ days) ( $p \leq 0.001)$. This probability continued to increase with decreasing $\mathrm{Hb}$ concentration in the preoperative anaemia group. The mean in days was 5.9 for mildly anaemic, 6.7 for the moderately anaemic, and 8.2 for the severely anaemic patients. After logistic regression analysis adjusting for potential confounders (statistically significant baseline characteristics and those with theoretically proven effects), preoperative anaemia remained independently and significantly associated with increased hospital length stay (Table 4).

(b) Complications before discharge: the details of the complications before discharge are shown in Table 5. There was no difference among groups regarding the composite complications $(p=0.101)$.

(c) Inhospital mortality: mortality data were available for the tertiary hospital (781) cases only. There was no difference among groups regarding inhospital mortality (mortality for anaemic group 8/398 (2.0\%) versus nonanaemic $4 / 383(1.0 \%),(p=0.273)$. Only $12(1.3 \%)$ inhospital mortalities were recorded. Mortality occurred between 0 and 28 days after surgery. Most of the mortality (66.7\%) occurred among emergency general surgery cases.

3.4. Effect of Perioperative Red Cells Transfusions on Preoperative Anaemia. Perioperative anaemia was treated mainly with allogeneic RBC transfusion followed by haematinics. Overall, $172(19.3 \%)$ patients received a total of 347 units of allogeneic RBC transfusion, 73 (8.2\%) patients received two units of RBCs, followed by 1 unit for $55(6.2 \%)$ patients, with the remaining patients receiving between 3 and 5 units. Overall, patients with preoperative anaemia received more perioperative transfusion than nonanaemic patients $(30.7 \%$ versus $5.6 \%, p \leq 0.001$; OR 7.42 , $95 \% \mathrm{CI}$ (4.67-11.79)). This difference was also consistent with preoperative transfusion $(12.8 \%$ versus $0.7 \%, p \leq 0.001)$, intraoperative transfusion ( $10.7 \%$ versus $1.5 \%, p \leq 0.001)$, and postoperative transfusion $(16.7 \%$ versus $4.2 \%$, $p \leq 0.001$ ), with some patients receiving transfusion in more than one phase of the perioperative phases.

By binary logistic regression analysis, independent predictors of RBC transfusion were severity of preoperative anaemia, severe and moderate anaemia (OR 16.83, 95\% CI (9.16-30.89), $p \leq 0.001$ ), and comorbid conditions (OR 2.57, 95\% CI (1.46-4.52), $p=0.001)$ after adjusting for confounding factors; non-RBC transfused group was used as a reference. Mild anaemia was not a predictor for transfusion (OR 1.29, 95\% CI (0.62-2.65), $p=0.495)$. After adjusting for these confounding factors including age and sex, perioperative RBC transfusion significantly and independently was associated with prolonged length of hospital stay. Severe and moderate anaemia became a stronger determinant for $\mathrm{RBC}$ transfusion $(p \leq 0.001)$. Comorbidity still remained a significant determinant (OR 2.22, 95\% CI (1.29-3.82), $p=0.004)$ of $\mathrm{RBC}$ transfusion. There was no significant 


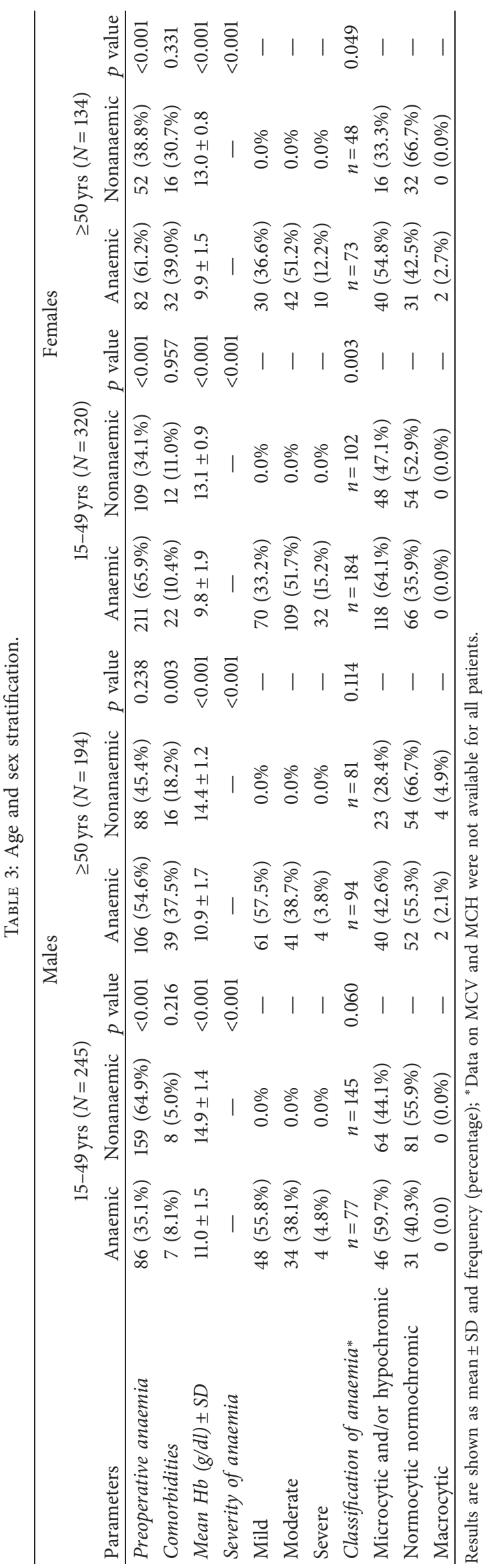


TABLE 4: Effects of preoperative anaemia on postoperative outcomes.

\begin{tabular}{lcc}
\hline Outcome & \multicolumn{2}{c}{ Preoperative anaemia } \\
\hline Prolonged LOS & $\mathrm{OR}_{\text {unadj }}(95 \% \mathrm{CI}) ; p$ value & $\mathrm{OR}_{\mathrm{adj}-1}(95 \% \mathrm{CI}) ; p$ value \\
Composite complication & $1.72(1.23-2.41) ; p=0.001$ & $2.12(1.49-3.10) ; p \leq 0.001$ \\
Inhospital mortality & $1.31(0.88-1.93) ; p=0.180$ & $0.97(0.63-1.49) ; p=0.874$ \\
\hline
\end{tabular}

Results are shown as odds ratio $(95 \% \mathrm{CI})$; patients without preoperative anaemia were used as the reference; $\mathrm{OR}_{\mathrm{unadj}}=$ unadjusted odds ratio; $\mathrm{OR}$ adj-1 $=$ odds ratio; LOS = length of hospital stay.

TABle 5: Postoperative complications.

\begin{tabular}{|c|c|c|c|c|}
\hline Parameter & Total $(N=893)$ & Preoperative anaemia $(n=485)$ & No preoperative anaemia $(n=408)$ & $p$ value \\
\hline Complications before discharge & & & & 0.101 \\
\hline Pain at incision site & $76(8.5 \%)$ & $42(8.7 \%)$ & $34(8.3 \%)$ & - \\
\hline Surgical site infection & $22(2.5 \%)$ & $17(3.5 \%)$ & $5(1.2 \%)$ & - \\
\hline Difficulty in breathing & $5(0.6 \%)$ & $3(0.6 \%)$ & $2(0.5 \%)$ & - \\
\hline Fever & $7(0.8)$ & $2(0.4 \%)$ & $5(1.2 \%)$ & - \\
\hline Palpitations & $4(0.4 \%)$ & $4(0.8 \%)$ & $0(0.0)$ & - \\
\hline Others & $6(0.7 \%)$ & $4(0.8 \%)$ & $2(0.5 \%)$ & - \\
\hline
\end{tabular}

Results are shown as frequency (percentage); others = hypoventilation and cardiogenic shock.

TABLE 6: Effects of red blood cell transfusion on outcome.

\begin{tabular}{llr}
\hline Logistic regression analyses (adjusted) & $\mathrm{OR}_{\mathrm{unadj}}(95 \% \mathrm{CI}) ; p$ value & $\mathrm{OR}$ adj-1 $(95 \% \mathrm{CI}) ; p$ value \\
\hline $\begin{array}{l}\text { P-LOS association with RBC transfusion } \\
\begin{array}{l}\text { Composite complication association with RBC } \\
\text { transfusion }\end{array}\end{array}$ & $3.81(2.64-5.50) ; p \leq 0.001$ & $4.48(2.67-7.51), p \leq 0.001$ \\
$\begin{array}{l}\text { Inhospital mortality association with RBC } \\
\text { transfusion }\end{array}$ & $5.80(1.82-18.53) ; p=0.004$ & $1.32(0.74-2.36) ; p=0.347$ \\
\hline
\end{tabular}

Results are shown as odds ratio (95\% CI); no RBC transfusion was used as a reference; $\mathrm{OR}_{\mathrm{adj}-1}=$ odds ratio adjusted for severity of anaemia, age, sex, comorbid conditions, surgical specialty, grade of surgery, and cancer; $\mathrm{CI}=$ confidence interval; $\mathrm{P}$-LOS = prolonged length of hospital stay; $\mathrm{RBC}=$ red blood cell.

association between inhospital mortality with perioperative $\mathrm{RBC}$ transfusion after adjusting for significant confounding factors as shown in Table 6.

For preoperative transfusion, 61/65 (93.8\%) of patients were haemo transfused within 2 weeks to the surgery. Additionally, $70 / 98(71.4 \%)$ of patients received their postoperative transfusion within 2 days after surgery. Some patients $(14 / 65 ; 21.5 \%)$ were transfused before hospital admission. The blood bank recorded two autologous predonations during the study period. However, the patients involved were not transfused; hence, all transfusions were allogeneic.

3.4.1. Cost Implications of Allogeneic RBC Transfusion. Data available from the blood bank records at the tertiary hospital and interview with patients indicated an approximate cost of 160.0 Ghanaian cedis (approximately 38.0 USD) for obtaining and processing one unit of replacement donation.

3.5. Haematinics. $180(20.2 \%)$ patients were treated with perioperative haematinics: 151 (31.1\%) for anaemic as compared to $28(6.9 \%)$ for nonanaemic patients $(p \leq 0.001)$. Preoperative haematinics use among anaemic versus nonanaemic patients was $12.0 \%$ versus $1.2 \%$ ( $p \leq 0.001)$. In addition, $122(25.2 \%)$ of the anaemic patients received haematinics postoperatively compared with 24 (5.9\%) of the patients without anaemia $(p \leq 0.001)$, with some patients receiving multiple modes of treatment. Oral iron was frequently used for perioperative anaemia treatment as shown in Table 7.

3.6. Exclusion. Excluded data did not skew the overall data, when analysed as shown in Table 8.

\subsection{Other Findings}

3.7.1. Postoperative Malaria. Postoperative malaria parasitaemia data were available for 423 patients. Positive patients who were symptomatic were treated before surgery. The prevalence rate of malaria parasitaemia in the entire study population increased from $2.5 \%$ preoperatively to $3.5 \%$ postoperatively $(p \leq 0.001)$. The prevalence rate increased from $3.2 \%$ before surgery to $4.2 \%(p \leq 0.001)$ after surgery among the anaemic patients and from $1.8 \%$ to $3.4 \%$ among the nonanaemic patients $(p \leq 0.001)$.

\section{Discussion}

A high prevalence of preoperative anaemia (approximately $54 \%$ ) in unselected noncardiac surgical patients was observed 
TABLE 7: Perioperative use of haematinics in the patients.

\begin{tabular}{|c|c|c|c|c|c|}
\hline Parameter & Patients total $(n)$ & Oral iron & Folate & Oral iron + folate & Others \\
\hline Perioperative & 893 & $74(8.3 \%)$ & $29(3.2 \%)$ & $38(4.3 \%)$ & $40(4.5 \%)$ \\
\hline \multicolumn{6}{|l|}{ Preoperative haematinics } \\
\hline Preoperative anaemia $^{a}$ & 485 & $28(5.8 \%)$ & $7(1.4 \%)$ & $9(1.9 \%)$ & $14(2.9 \%)$ \\
\hline No preop. anaemia ${ }^{a}$ & 408 & $2(0.5 \%)$ & $1(0.2 \%)$ & $0.0 \%$ & $2(0.5 \%)$ \\
\hline \multicolumn{6}{|l|}{ Postoperative haematinics } \\
\hline Preoperative anaemia ${ }^{a}$ & 485 & $47(9.7 \%)$ & $26(5.4 \%)$ & $39(8.0 \%)$ & $23(4.7 \%)$ \\
\hline No preop. anaemia ${ }^{a}$ & 408 & $7(1.7 \%)$ & $5(1.2 \%)$ & $5(1.2 \%)$ & $17(4.2 \%)$ \\
\hline
\end{tabular}

Results are presented as percentages; ${ }^{a}$ more than one treatment per patient is possible, that is, some patients received a combination of pre- and/or posthaematinics treatments; others = oral iron and/or folate administered with vitamin $\mathrm{B}_{12}$, erythropoietin, or zinc; no patient received haematinics intraoperatively.

TABLE 8: Analysis of excluded data.

\begin{tabular}{|c|c|c|c|c|}
\hline Parameter & Total $^{*}(N=60)$ & PA $(n=41)$ & No PA $(n=18)$ & $p$ value \\
\hline Age, mean (range) & $44.2(16-90)$ & $47.0(15-86)$ & $46.0(16-83)$ & 0.027 \\
\hline $\operatorname{Sex}, n(\%)$ & & & & 0.347 \\
\hline Females & $21(35.6 \%)$ & $13(31.7 \%)$ & $8(44.4 \%)$ & - \\
\hline Males & $38(64.4 \%)$ & $28(68.3 \%)$ & $10(55.6 \%)$ & - \\
\hline \multicolumn{5}{|l|}{ Preoperative $\mathrm{Hb}$ concentration } \\
\hline Mean $\mathrm{Hb} \pm \mathrm{SD}$ & $11.2 \pm 2.5 \mathrm{~g} / \mathrm{dl}$ & $9.9 \pm 1.8 \mathrm{~g} / \mathrm{dl}$ & $14.0 \pm 1.1 \mathrm{~g} / \mathrm{dl}$ & $<0.001$ \\
\hline Mild anaemia & - & $13(21.0 \%)$ & - & - \\
\hline Moderate anaemia & - & $24(40.7 \%)$ & - & - \\
\hline Severe anaemia & - & $4(6.8 \%)$ & - & - \\
\hline Surgical specialty, $n$ (\%) & & & & 0.670 \\
\hline General surgery & $33(55.9 \%)$ & $23(56.1 \%)$ & $10(55.6 \%)$ & - \\
\hline Gynaecology & $1(1.7 \%)$ & $1(2.4 \%)$ & $0(0.0 \%)$ & - \\
\hline Orthopaedics & $16(27.1 \%)$ & $13(31.7 \%)$ & $5(27.8 \%)$ & - \\
\hline Urology & $4(6.8 \%)$ & $3(7.3 \%)$ & $1(5.6 \%)$ & - \\
\hline Plastics & $2(3.4 \%)$ & $1(2.4 \%)$ & $1(5.6 \%)$ & - \\
\hline Ear, nose, and throat (ENT) & $24(2.7 \%)$ & $13(2.7 \%)$ & $11(2.7 \%)$ & - \\
\hline Neurosurgery & $1(1.7 \%)$ & $0(0.0 \%)$ & $1(5.6 \%)$ & - \\
\hline Sickling status $(n=24)$ & & & & 0.746 \\
\hline Positive & $8(20.8 \%)$ & $3(16.7 \%)$ & $2(33.3 \%)$ & - \\
\hline Negative & $19(79.2 \%)$ & $15(83.3 \%)$ & $4(66.7 \%)$ & - \\
\hline Comorbidity $(n=54)$ & & & & 0.245 \\
\hline Yes & $15(27.8 \%)$ & $13(33.3 \%)$ & $2(13.3 \%)$ & - \\
\hline No & $39(72.2 \%)$ & $26(66.7 \%)$ & $13(86.7 \%)$ & - \\
\hline LOS mean $\pm S D$ (days) $(n=49)$ & $33.3 \pm 17.8$ & $35.8 \pm 17.0$ & $27.7 \pm 19.0$ & 0.632 \\
\hline Mortality $(n=54)$ & & & & 0.675 \\
\hline Yes & $2(3.7 \%)$ & $2(5.3 \%)$ & $0(0.0 \%)$ & - \\
\hline Complications $(n=54)$ & & & & 0.797 \\
\hline Yes & $21(38.9 \%)$ & $14(36.8 \%)$ & $7(43.8 \%)$ & - \\
\hline Perioperative transfusion $(n=55)$ & & & & 0.499 \\
\hline Yes & $19(34.5)$ & $15(39.5 \%)$ & $4(23.5 \%)$ & - \\
\hline
\end{tabular}

* One patient had a high $\mathrm{Hb}$ level; hence, that patient was not included in the analysis; 59 samples were analysed; LOS=length of hospital stay, $\mathrm{PA}=$ preoperative anaemia.

in our study, but most had moderate anaemia. Overall, $57 \%$ of anaemic admissions had microcytic and/or hypochromic indices, consistent with possible iron deficiency, but normocytic normochromic indices were prevalent in the elderly
(65 years and above) together with a significantly higher comorbidities, indicating a possible anaemia of chronic disease or inflammation. The preoperative anaemia resulted in prolonged postoperative hospital stay when compared with the 
nonanaemic patients. Composite complications and inhospital mortality were more frequent among the anaemic patients though not statistically significant. In this study, about $31 \%$ of preoperative anaemia patients received perioperative transfusion with an overall mean of two units per patient. The independent determinants for blood transfusion were the severity of the preoperative anaemia and comorbid condition. Perioperative transfusion was significantly associated with poor postoperative outcomes.

This study is in agreement with other studies showing high levels of preoperative anaemia among unselected surgical patients [8] and among elective orthopaedic patients [3]. However, the high prevalence rate of $54 \%$ despite the preoperative transfusion and haematinics use contradicts previous studies of about 29\% [8], 25\% [15], and 14\% [3]. Approximately, $47 \%$ prevalence rate was reported among nonpregnant Ghanaian women of reproductive age (15-49 years) in the Central Region of Ghana using the WHO criteria [16]. But our findings showed a higher prevalence rate of about $66 \%$ among women in the reproductive age group even though women formed $50.8 \%$ of the study population. Olayemi and colleagues reported approximately $52 \%$ anaemia among apparently healthy young Nigerian adults [17].

Saleh and colleagues [18] reported 23\% possible iron deficiency among 1142 elective major joint arthroplasty patients aged 15-91 years using hypochromasia as an index. Our study recorded approximately $57 \%$ anaemic patients with microcytosis and/or hypochromasia. About $64 \%$ of females in the reproductive age group had microcytic and/or hypochromic indices. This is in line with the high prevalence of iron deficiency among black Africans including Ghanaians. A prevalence of $32.0 \%$ was reported among Ghanaian women living in Germany [19], 41-63\% iron deficiency among Ivoirians women [20], and 39\% IDA among Nigerians women aged 16-45 years [21]. Thalassaemia is equally prevalent in Ghanaians, alpha-thalassaemia is about 34\% [19] and betathalassaemia is about 5\% [22], but could not be differentiated due to restriction on confirmatory investigations at the selected centres. Anaemia of chronic diseases could not also be excluded.

$61 \%$ of the elderly patients had anaemia which was mostly mild with normocytic normochromic indices. They also had significant comorbidities suggesting possible anaemia of chronic disease or inflammation.

Regarding outcomes, preoperative anaemia remained an independent risk factor for prolonged hospital stay after adjusting for potential confounders. Some observational studies in noncardiac surgical patients emphasize this association $[9,23]$.

The overall composite complication before discharge was $13.4 \%$. Although comorbidity was significantly greater in preoperative anaemia patients, the anaemia did not significantly modify the composite complication. However, other studies have found anaemia to be an independent predictor for postoperative complications $[6,8]$. This is probably due to the inability of this study to capture complications such as renal insufficiency. The short duration in which the complications were recorded may be a contributing factor.
Our study did not show a significant association between preoperative anaemia and inhospital mortality. This agrees with the findings of Greenky and colleagues [24] and Munoz and colleagues [25]. However, Baron et al. [8] found preoperative anaemia to be significantly and independently associated with inhospital mortality. Saager and colleagues [15] found anaemia to be a weak independent predictor of 30-day postoperative mortality.

Our study is also in agreement with previous studies showing preoperative anaemia to be an independent and strong predictor for increased perioperative $\mathrm{RBC}$ transfusion $[3,7]$. The result of this study suggests that allogeneic RBC transfusion is significantly associated with prolonged length of hospital stay, higher complications, and higher mortality. After correcting for patients characteristics, prolonged length of hospital stay remained independently and significantly associated with allogeneic RBC transfusion [3].

This study recorded a relatively low perioperative transfusion rates compared to the high prevalence of preoperative anaemia. This may be reflective of the type of surgery, the sample size, and amounts of blood loss (which was not captured). Some patients could not get replacement donors and had to be discharged with fewer units of blood transfused or without being transfused when the Hb level was not lifethreatening. In the hospitals where the research was carried out, voluntary blood donation is not common; hence, patients have to rely on replacement donation which can be difficult to obtain. Transfusion attracts an extra financial burden on the patient which most cannot afford.

Despite recent recommendations advising investigating the cause of anaemia and treating it preoperatively to minimise transfusion requirements in elective surgical patients, the percentage of anaemic patients treated preoperatively was very low, about $12 \%$. Preoperative oral or parenteral iron or postoperative parenteral iron with or without erythropoietin-stimulating therapy is useful for the management of perioperative anaemia $[8,18]$.

Traumatic events like tissue damage, blood loss, and surgery trigger cascades of inflammatory mediators to cause immunodepression with increased risk to develop malaria parasitaemia [26]. In a study among traumatized land mine and war victims in Cambodia [27], about 33\% of asymptomatic malaria carriers developed posttrauma and postsurgery symptomatic malaria. Our study showed a significant increased prevalence rate of postoperative malaria parasitaemia in agreement with these findings [26, 27]. Ghana being an endemic area for malaria, the immunosuppression due to surgery predisposes patients to malaria parasitaemia. However, very few of the patients in this study were symptomatic postoperatively. Our study, however, contradicts the study by Takongmo and colleagues [28], which showed that the development of postoperative malaria was not significantly associated with the surgical trauma.

\section{Limitations}

About $1.5 \%$ of the preoperative $\mathrm{Hb}$ concentrations were obtained more than 28 days prior to the surgery and may not have represented the actual $\mathrm{Hb}$ level at the time of surgery. 
Approximately $6.8 \%$ of the patients were on preoperative haematinics, and $7.3 \%$ were transfused prior to the surgery; however, there was no repeat of the Hb levels for a number of the patients after the initial assessment.

Postoperative $\mathrm{Hb}$ levels were not available for most patients; hence, their effects could not be analysed.

Also, anaemia was classified based on only mean corpuscular volume (MCV) and mean corpuscular haemoglobin $(\mathrm{MCH})$; increased reticulocyte count due to compensatory response to anaemia and/or the preoperative haematinics administered to some patients can spuriously raise the MCV value masking microcytosis. Confirmatory tests such as ferritin or soluble transferrin receptor measurement for the diagnosis of iron deficiency are not routinely performed at the selected centres. Additionally, data on renal and liver function were not uniformly available for most patients and hence not captured.

\section{Conclusion}

Preoperative anaemia is common among noncardiac surgery patients. It is independently and significantly associated with prolonged hospital stay leading to increased healthcare resource use. It is also the main predictor for perioperative allogeneic blood transfusions and the use of haematinics.

This study has potential implications for improving the perioperative management of noncardiac surgery patients in the Central Region and Ghana as a whole. It will enhance adequate preparation and comprehensive care to minimise known complications associated with preoperative anaemia. It will also serve as a pilot for a wider national study on postoperative outcomes among noncardiac surgery patients.

\section{Abbreviations}

Hb: Haemoglobin

RBC: Red blood cells

MCV: Mean corpuscular volume

$\mathrm{MCH}$ : Mean corpuscular haemoglobin.

\section{Ethical Approval}

The study was approved by the Institutional Review Board of the University of Cape Coast (approval reference: $\mathrm{UCC} / \mathrm{IRB} / 3 / 1)$.

\section{Consent}

Written permission was sought from the Management of the Cape Coast Teaching Hospital and Saint Luke's Catholic Hospital, Apam. Written informed consent was obtained from all individual patients or their guardians.

\section{Disclosure}

Gladys Amponsah is currently at School of Anaesthesia, Greater Accra Regional Hospital, Accra, Ghana.

\section{Conflicts of Interest}

The authors declare that there are no conflicts of interest regarding the publication of this paper.

\section{Authors' Contributions}

Both authors contributed equally and read and approved the final manuscript.

\section{Acknowledgments}

The authors are extremely grateful to Professor Samuel Debrah, the then Head of the Department of Surgery, for reviewing and editing the proposal and the manuscript. The authors are also thankful to the entire surgical suite staff, all surgeons, clinicians, nurse anaesthetists, and nurses for helping in retrieving data from the patients' medical records. The authors thank the diagnostic laboratory unit for assisting with the sickling test. The authors also thank Dr. Daniel Asare, the CEO of Cape Coast Teaching Hospital, and Dr. Samuel Kwashie, Central Regional Director Ghana Health Services, for donating the malaria rapid test kits used for the study and Sister Mary Magdalene Mary Arthur, Matron of Saint Luke's Catholic Hospital, Apam, for her support. Special thanks are due to Mr. Joseph Obodai who assisted with the data collection; Dr. Kingsley Kwadwo Asare Pereko of the Department of Community Medicine, University of Cape Coast, School of Medical Sciences, and Dr. Michael Owusu of KCCR, Kumasi, for assisting with the data analysis; and Dr. Yvonne Dei-Adomakoh, a clinical haematologist, for reviewing the manuscript.

\section{References}

[1] A. Rammohan, N. Awofeso, and R. Marie-Claire, "Addressing female iron-deficiency anaemia in India: is vegetarianism the major obstacle?," ISRN Public Health, vol. 2012, Article ID 765476, 8 pages, 2012.

[2] J. Barbieri, P. C. Fontela, E. R. Winkelmann et al., "Anemia in patients with type 2 diabetes mellitus," Anemia, vol. 2015, Article ID 354737, 7 pages, 2015.

[3] S. Lasocki, R. Krauspe, C. von Heymann, A. Mezzacasa, S. Chainey, and D. R. Spahn, "PREPARE: the prevalence of perioperative anaemia and need for patient blood management in elective orthopaedic surgery: a multicentre, observational study," European Journal of Anaesthesiology, vol. 32, no. 3, pp. 160-168, 2015.

[4] H. Gombotz, P. H. Rehak, A. Shander, and A. Hofmann, "Blood use in elective surgery: the Austrian benchmark study," Transfusion, vol. 47, no. 8, pp. 1468-1480, 2007.

[5] S. A. Ali, A. G. Soomro, A. I. Memon, and A. J. Siddiqui, "Prevalence, evaluation and management of preoperative anaemia in the elective general surgical patients," Journal of Ayub Medical College, Abbottabad, vol. 24, no. 3-4, pp. 59-61, 2012.

[6] K. M. Musallam, H. M. Tamim, T. Richards et al., "Preoperative anaemia and postoperative outcomes in noncardiac surgery: a retrospective cohort study," The Lancet, vol. 378, no. 9800, pp. 1396-1407, 2011.

[7] T. Richards, K. M. Musallam, J. Nassif et al., "Impact of preoperative anaemia and blood transfusion on postoperative 
outcomes in gynaecological surgery," PLoS One, vol. 10, no. 7, Article ID e01308, 2015.

[8] D. M. Baron, H. Hochrieser, M. Posch et al., "Preoperative anaemia is associated with poor clinical outcome in noncardiac surgery patients," British Journal of Anaesthesia, vol. 113, no. 3, pp. 416-423, 2014.

[9] S. Jayaraman, Z. Chalabi, P. Perel, C. Guirriero, and I. Roberts, "The risk of transfusion-transmitted infections in sub-Saharan Africa," Transfusion, vol. 50, no. 2, pp. 433-442, 2010.

[10] T. Saachai and J. Lin, "Anesthetic aspect of malaria disease: a brief review," Middle East Journal of Anaesthesiology, vol. 21, no. 4, pp. 457-462, 2012.

[11] WHO, "Haemoglobin concentrations for the diagnosis of anaemia and assessment of severity," April 2017, http://www. WHO_NMH_NHD_MNM_11.1_eng.pdf.

[12] BUPA, "Schedule of procedures," January 2017, http://www. cambridgevascularaccess.com/userfiles/BUPAScheduleofProcedures1. pdf.

[13] H. R. Abdullah, Y. E. Sim, Y. Hao et al., "Association between preoperative anaemia with length of hospital stay among patients undergoing primary total knee arthroplasty in Singapore: a single-centre retrospective study," BMJ Open, vol. 7, no. 6, p. e016403, 2017.

[14] A. Almashrafi, H. Alsabti, M. Mukaddirov, B. Balan, and P. Aylin, "Factors associated with prolonged length of stay following cardiac surgery in a major referral hospital in Oman: a retrospective observational study," BMJ Open, vol. 6, no. 6, p. e010764, 2016.

[15] L. Saager, A. Turan, L. F. Reynolds, J. E. Dalton, E. J. Mascha, and A. Kurz, "The association between preoperative anemia and 30-day mortality and morbidity in noncardiac surgical patients," Anesthesia \& Analgesia, vol. 117, no. 4, pp. 909-915, 2013.

[16] Ghana Demographic and Health Survey. 2014; 30-31, April 2017, http://www.statsghana.gov.gh/docfiles/publications/ Ghana\%20DHS\%202014\%20-\%20KIR\%20-\%206\%20April\% 202015.pdf.

[17] E. Olayemi and N. K. D. Halim, "Anaemia in apparently healthy adult Nigerians," Journal of College of Medicine, vol. 10, no. 1, pp. 31-33, 2005.

[18] E. Saleh, D. B. L. McClelland, A. Hay, D. Semple, and T. S. Walsh, "Prevalence of anaemia before major joint arthroplasty and the potential impact of preoperative investigation and correction on perioperative blood transfusions," British Journal of Anaesthesia, vol. 99, no. 6, pp. 801-808, 2007.

[19] S. A. Muller, S. K. B. Amoah, S. Meese, J. Spranger, and F. P. Mockenhaupt, "High prevalence of anaemia among African migrants in Germany persists after exclusion of iron deficiency and erythrocyte polymorphisms," Tropical Medicine and International Health, vol. 20, no. 9, pp. 1180-1189, 2015.

[20] F. S. Asobayire, P. Adou, L. Davidsson, J. D. Cook, and R. F. Hurrell, "Prevalence of iron deficiency with and without concurrent anemia in population groups with high prevalences of malaria and other infections: a study in Côte d'Ivoire," American Journal of Clinical Nutrition, vol. 74, no. 6, pp. 776-782, 2001.

[21] A. J. Esan, "Prevalence and evaluation of iron deficiency anemia in anemic hospitalized patients in Osogbo, Nigeria," Journal of Hematology, Blood Transfusion and Disorders, vol. 3, no. 1, pp. 1-6, 2016.

[22] F. I. D. Konotey-Ahulu and B. Ringelhann, "Sickle-cell anaemia, sickle-cell thalassaemia, sickle-cell haemoglobin C disease, and asymptomatic haemoglobin $\mathrm{C}$ thalassaemia in one Ghanaian family," British Medical Journal, vol. 1, no. 5644, pp. 607-612, 1969.

[23] S. W. Leichtle, N. J. Mouawad, R. Lampman, B. Singal, and R. K. Cleary, "Does preoperative anemia adversely affect colon and rectal surgery outcomes?," Journal of the American College of Surgeons, vol. 212, no. 2, pp. 187-194, 2011.

[24] M. Greenky, K. Gandhi, L. Pulido, C. Restrepo, and J. Parvizi, "Preoperative anemia in total joint arthroplasty: is it associated with periprosthetic joint infection?," Clinical Orthopaedics and Related Research, vol. 470, no. 10, pp. 2695-2701, 2012.

[25] M. Muñoz, D. Ariza, S. Gómez-RamÍrez, P. Hernández, J. A. García-Erce, and R. Santiago, "Preoperative anemia in elective cardiac surgery: prevalence, risk factors, and influence on postoperative outcome," Transfusion Alternatives in Transfusion Medicine, vol. 11, no. 2, pp. 47-56, 2010.

[26] M. Sundet, T. Heger, and H. Husum, "Post-injury malaria: a risk factor for wound infection and protracted recovery," Tropical Medicine and International Health, vol. 9, no. 2, pp. 238-242, 2004.

[27] H. Husum, T. Heger, and M. Sundet, "Postinjury malaria: a study of trauma victims in Cambodia," Journal of Trauma and Acute Care Surgery, vol. 52, no. 2, pp. 259-266, 2002.

[28] S. Takongmo, J. Gaggini, E. Malonga, H. Leundji, and A. Same Ekobo, "Malaria and post operative fever in the University Hospital Center of Yaounde (Cameroon)," Médecine Tropicale, vol. 53, no. 1, pp. 97-100, 1993. 


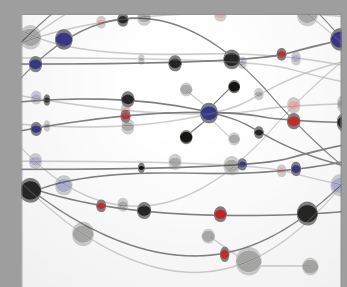

The Scientific World Journal
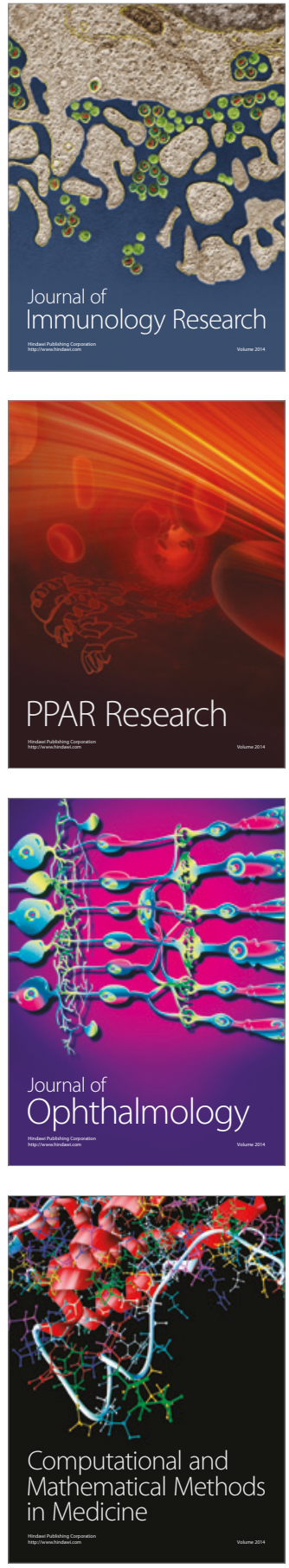

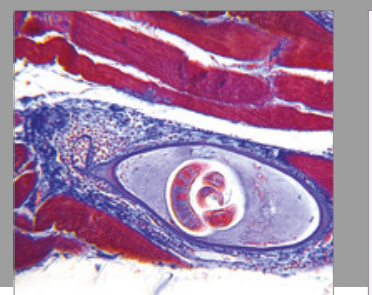

Gastroenterology Research and Practice
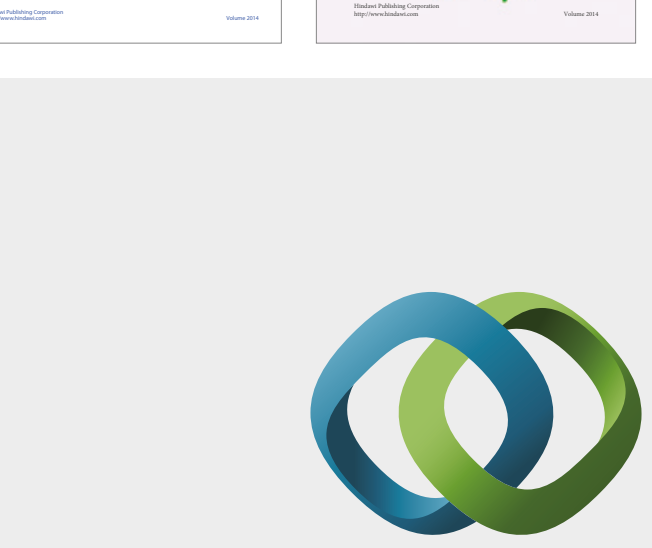

\section{Hindawi}

Submit your manuscripts at

https://www.hindawi.com
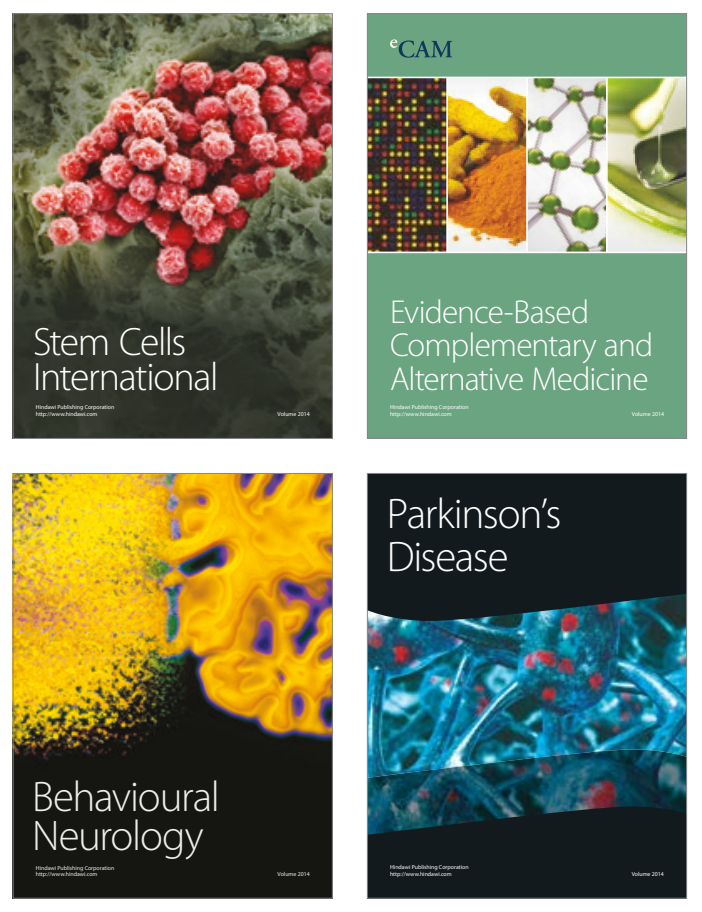
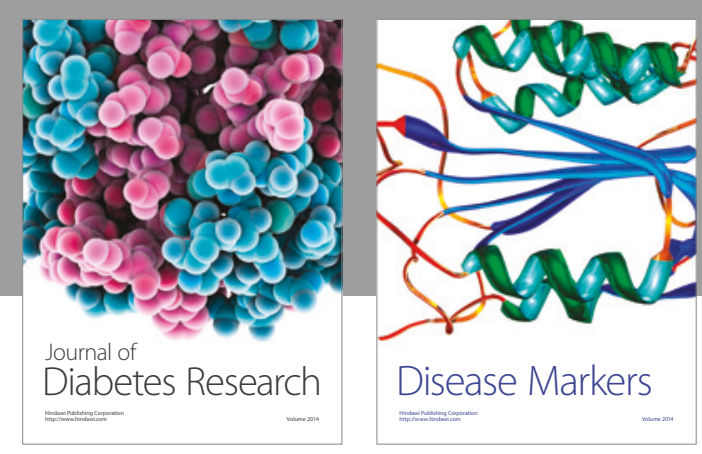

Disease Markers
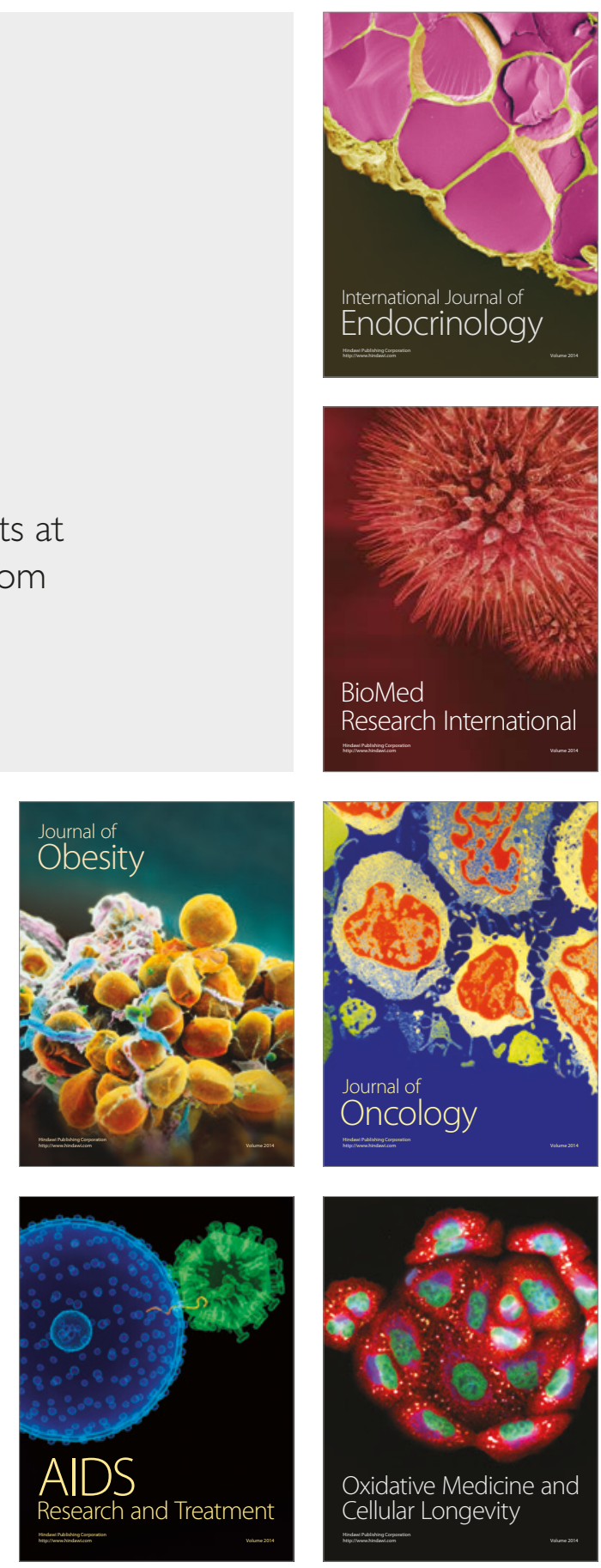